\title{
ANALISIS DAN IMPLEMENTASI WEB USAGE MINING MENGGUNAKAN ALGORITMA SEQUENTIAL PATTERN DISCOVERY USING EQUIVALENCE CLASSES SPADE
}

\section{(Studi Kasus: Website iGracias Universitas Telkom)}

\author{
${ }^{1)}$ Asri Inna Khoirun Nissa, ${ }^{2)}$ Ibnu Asror, ${ }^{3)}$ Gede Agung Ary W \\ ${ }^{1,2,3)}$ Fakultas Informatika \\ Universitas Telkom \\ Jl. Telekomunikasi No.1 \\ 1)asriinna@gmail.com, ${ }^{2}$ iasror@ @elkomuniversity.ac.id, ${ }^{3)}$ ary.wisudiawan@ @elkomuniversity.ac.id
}

\begin{abstract}
Abstrak
Website Igracias Universitas Telkom merupakan salah satu website di universitas Telkom yang sering digunakan oleh seluruh entitas Universitas Telkom. Pola pengunjungan web dapat digunakan untuk mengetahui halaman apa saja yang telah dikunjungi oleh user dalam suatu website. Salah satu ilmu yang mempelajari pola navigasi user agar mendapatkan suatu informasi yang bermanfaat adalah web usage mining. Pada penelitian ini algoritma yang digunakan adalah sequential pattern discovery using equivalence classes (SPADE). Algoritma SPADE diterapkan untuk mencari pola perilaku pengguna website dengan cara melakukan preprocessing data untuk menyaring informasi yang dibutuhkan. Dilanjutkan dengan pembentukan data transaksi dan perhitungan SPADE dengan mengkombinasikan itemset dan menghitung frequent-nya untuk mendapatkan rule yang kemudian dicari kekuatan setiap rule dengan menghitung lift ratio-nya.
\end{abstract}

Kata kunci : web usage mining, SPADE.

\begin{abstract}
Igracias Telkom University is one of the Telkom University website that are frequently used by the entire entity of the by all entities that exist at Telkom University. The pattern of the web can be used recursively to find out what pages have been visited by the user on a website. One of the study of the patterns of user navigation in order to obtain a useful information is a web usage mining. On this final project, the algorithm used is a sequential
\end{abstract}

pattern discovery using equivalence classes (SPADE). The SPADE algorithm is applied to search behavior patterns by preprocessing data to find out the useful information or knowledge. Proceed with the establishment of the data transaction and calculation of the SPADE by combining itemset and calculate the frequent to get a rules which will then look for the strength of each rule by calculating the lift ratio.

Keywords : web usage mining, SPADE

\section{Pendahuluan}

Sebuah pengembangan pesat telah terjadi di dunia internet. Internet sekarang ini memiliki akses informasi yang jauh lebih luas dan fungsi yang lebih beragam. Perkembangan internet juga diiringi dengan pemanfaatan website dalam berbagai bidang. Terutama dibidang pendidikan seperti penggunaan website kampus untuk menampung segala informasi dan aktivitas user yang ada pada lingkungan tersebut. Untuk meningkatkan kualitas dari sebuah website, aktivitas user ini dapat digunakan untuk melihat pola navigasi user dengan menggunakan teknik web mining. Web mining pada dasarnya merupakan sebuah teknik untuk penggalian data yang berhubungan dengan web. Web mining terbagi menjadi tiga yaitu, web content mining, web structure mining dan web usage mining. Pada web usage mining atau biasa disebut dengan web log mining digunakan untuk menganalisis pola penggunaan user pada web yang berfungsi untuk pengembangan aplikasi web. Terdapat beberapa teknik untuk menentukan aturan 
atau pola pada web mining diantaranya statistical analysis, association rules, sequential rules, clustering dan classification (Mehak, Kumar, \& Aggarwal, 2013).

Pada penelitian ini dilakukan web mining pada website Igracias Universitas Telkom. Website Igracias merupakan sebuah website pendidikan yang digunakan oleh universitas Telkom. Website ini menampung semua data atau informasi dari setiap aktivitas elemen kampus diantaranya dosen, mahasiswa dan pegawai. Untuk mendukung aktivitas user ini, perlu dilakukan analisa untuk perbaikan dan pengembangan yang dapat dijadikan bahan evaluasi terhadap website igracias dengan menggunakan event $\log$. Dikarenakan data event log ini merupakan data yang sekuensial atau berkelanjutan maka untuk memecahkan masalah ini digunakan sebuah metode yang bernama sequential pattern mining (Mooney \& Roddick, 2013). Sequential pattern mining digunakan untuk mencari data yang memiliki urutan, data tersebut bisa merupakan urutan transaksi. Salah satu algoritma dari Sequential Pattern Mining adalah algoritma Sequential Pattern Discovery Using Equivalance Classes (SPADE) (Zaki, 2001). Algoritma sequential pattern discovery using equivalent classes (SPADE) merupakan salah satu algoritma dari sequential pattern mining yang digunakan untuk menemukan pola agar mendapatkan informasi yang berguna.

Algoritma SPADE menghasilkan performa yang jauh lebih baik dalam hal waktu komputasi dibandingkan algoritma-algoritma pencari frequent sequences sebelumnya seperti algoritma Apriori dan GSP (Generalized Sequential Pattern) (Gunawan, 2015). Dengan latar belakang tersebut maka metode sequential pattern mining dengan algoritma SPADE diharapkan cocok untuk menemukan pola perilaku pengguna website Igracias Universitas Telkom..

\section{KAJIAN LITERATUR}

\section{II.1 Web Mining}

Data mining merupakan sebuah proses yang digunakan untuk menemukan sebuah pola dalam data yang besar. Penerapan data mining dalam teknik data web untuk menemukan pengetahuan yang biasa disebut dengan web mining (Vijiyarani \& Suganya, 2015). Data yang sebenarnya lebih bervariasi dan memiliki pendekatan yang berbeda. Beberapa peneliti menerapkan teknik pada web logs yang dikelola oleh server yang dapat digunakan untuk menemukan user access dan traversals path.

Web mining dikategorikan menjadi tiga jenis, yaitu:

1. Web Content Mining: melakukan scanning dan penambangan data teks, gambar dari sebuah halaman web untuk menentukan relevansi dari sebuah konten pencarian. Penelitian dibidang ini menggunakan teknik dari disiplin ilmu lain seperti Information Retrieval (IR) dan Natural Language Processing (NLP).

2. Web Structure Mining: merupakan alat yang digunakan untuk mengidentifikasi hubungan antar halaman web. Motif dari structure mining adalah menghasilkan ringkasan terstruktur mengenai informasi dari sebuah halaman web.

Web Usage Mining: memungkinkan pengumpulan informasi pada halaman web. Data pada web usage mining mengarah pada halaman web yang diakses. Dan web server menyimpan segala informasi ini secara otomatis dalam sebuah access log.

\section{II.2 Web Usage Mining}

Web Usage Mining digunakan untuk menganalisis web log files untuk menemukan pola pengguna dalam mengakses sebuah halaman web. Web usage mining merupakan fokus utama dalam web mining yang mempelajari interaksi dari pengguna web. Web usage mining digunakan untuk menemukan pola yang bermakna dari data yang dihasilkan oleh transaksi client-server pada satu atau lebih web server (Mehak et al., 2013).

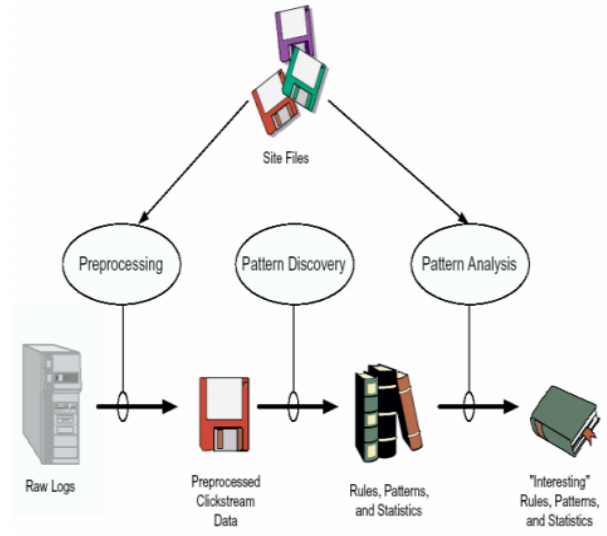

Asri Inna Khoirun Nissa, Ibnu Asror, Gede Agung Ary W 


\section{Gambar 1. Proses pada Web Usage Mining}

Web usage mining dikategorikan ke dalam tiga fase (Valera \& Chauhan, 2013):

1. Preprocessing: Berdasarkan klien, server dan server proxy, preprocessing adalah pendekatan pertama untuk mengambil data mentah dari sebuah web dan memproses data. Secara otomatis mengubah data mentah untuk digunakan pada proses selanjutnya.

2. Pattern Discovery: Berdasarkan dari data preprocessing, data mentah yang ada digunakan untuk menemukan pengetahuan dan menerapkan teknik yang akan digunakan pada machine learningyang menggunakan prosedur dari data mining.

Pattern Analysis: Pattern Analysis adalah proses setelah penemuan pola. Pattern Analysis memeriksa apakah pola yang ada pada web benar dan memandu proses ekstraksi informasi atau pengetahuan dari web.

\section{II.3 Preprocessing}

Beberapa database memiliki data yang tidak konsisten dan terdapat noise. Preprocessing digunakan untuk mentransformasi data tersebut. Hasil dari preprocessing membuat data menjadi lebih terintegrasi dan konsisten sehingga membentuk database yang stabil. Beberapa tahapan yang ada pada preprocessing (Varnagar, Madhak, Kodinariya, \& Rathod, 2013):

1. Data cleaning: proses mengidentifikasi, memilih dan menghapus data dari hal-hal yang tidak diperlukan atau tidak relevan.

2. User and Session Identification: tugas utama pada tahap ini adalah untuk mengidentifikasi user yang berbeda sesi dari akses log. Beberapa metode digunakan untuk mengidentifikasi sesi dari alamat IP yang berbeda untuk membedakan user.

\section{II.4 Event Log}

Event log merupakan catatan history yang memuat rangkaian aktivitas yang dilakukan pengguna dalam sebuah sistem informasi (Hermawan, 2014). Event log pada sistem informasi memuat catatan proses yang dilakukan oleh tiap pengguna. Setiap event log juga memiliki berbagai atribut seperti case_id, activity, time, cost dan resource. Namun tidak semua atribut tersebut selalu ada pada suatu event log. Misalnya adalah tidak adanya atribut resource maupun cost, tergantung dari data yang diperoleh dari suatu sistem informasi.

\section{II.5 Event Log}

Sampai saat ini telah dikenal beberapa algoritma yang dikembangkan khusus untuk mendapatkan pola sekuensial. Masing-masing algoritma menggunakan pendekatan yang berbeda-beda. Algoritma apriori Sequential Pattern Discovery using Equivalence Classes adalah salah satu algoritma sequential pattern mining yang menggunakan format data vertikal pada database sequence. Dalam format data vertikal, database sequence menjadi berbentuk kumpulan urutan yang formatnya [itemset: (sequence_ID, event_ID)], dengan kata lain, untuk setiap itemset akan disimpan sequence identifier dan event identifier yang berkoresponden. Event Identifier berguna sebagai timestamp atau penanda waktu dari itemset tersebut. Sepasang (sequence_ID, event_ID) untuk setiap itemset membentuk ID_list dari itemset tersebut (Zaki, 2001).

Langkah-langkah algoritma SPADE dalam mencari frequent sequence kemudian menentukan rule dari frequent sequence tersebut adalah sebagai berikut (Zaki, 2001):

1. Menghitung frequent 1-sequence Untuk mencari frequent 1 -sequence yang harus dilakukan pertama kali adalah mendaftar semua item yang terdapat pada database transaksi. Setiap item akan dicari nilai support-nya dengan cara menjumlahkan SID yang memiliki item tersebut. Jumlah dari SID merupakan nilai support dari item tersebut. Setelah semua item ditemukan nilai support-nya maka, item yang memiliki nilai support lebih dari sama dengan nilai minimum support merupakan item frequent 1-sequence.

2. Menghitung frequent 2-sequence Dalam mencari frequent 2-sequence, data yang digunakan adalah data dari frequent 1- sequence, sehingga tidak perlu mencari dari sequence database lagi. Untuk setiap masing-masing frequent 1sequence akan digabungkan dengan semua frequent 1-sequence lainnya. Contohnya jika 1sequence A digabungkan dengan 1-sequence $\mathrm{B}$ maka kemungkinan 2 sequence yang terjadi 
adalah A,B dimana A dan B muncul bersamaan dalam satu transaksi (satu SID, satu EID), A->B dimana item B muncul setelah item A, dan B->A dimana item A muncul setelah item B (satu SID, beda EID). Untuk setiap masing-masing penggabungan frequent 1 -sequence ini dilakukan pengecekan apakan eid dari 1-sequence A sama dengan,kurang dari atau lebih dari eid 1 - sequence B. apabila sama maka id-listnya dimasukkan dalam 2-sequence A,B. jika eid B lebih besar dari A maka id-listnya dimasukkan dalam 2-sequence A->B dan jika eid A lebih besar dari B maka id-listnya dimasukkan dalam 2-sequence B->A. kemudian seperti dalamfrequent 1-sequence id-list akan ditambahkan supportnya untuk setiap masingmasing sid yang sebelumnya belum ditemui. Dari 2-sequence itu kemudian dilakukan pengecekan apakah support-nya lebih dari nilai minimum support. Jika memenuhi syarat maka dimasukkan dalam frequent 2-sequence.

3. Menentukan frequent $\mathrm{k}$-sequence Setelah mencari frequent 2-sequence, untuk mencari frequent sequence- frequence sequence berikutnya dilakukan proses yang sama, yatu mencari frequent $\mathrm{k}$-sequence. Untuk mencari frequent $k$-sequence ini dilakukan join pada frequent (k-1) sequence yang memiliki prefix yang sama. Contohnya untuk mencari 3sequence kita digabungkan frequent sequence dari 2-sequence yang memiliki prefix yang sama, untuk mencari 4-sequnce digabungkan frequent sequence dari 3-sequence yang memiliki prefix yang sama, dan seterusnya. Untuk mencari prefix frequent (k-1), sequence akan menghilangkan item terakhir dari sequence tersebut. Contoh jika terdapat 4-sequence $\mathrm{A}$-> B-> C $\rightarrow$ D, maka prefixnya adalah A->B->C. untuk setiap penggabungan ini ada 3 kemungkinan hasil:

a. Jika A,B digabungkan dengan A,C maka kemungkinan hasilnya hanya A,B,C. b. Jika A,B digabungkan dengan $\mathrm{A}->\mathrm{C}$, maka kemungkinan hasilnya A,B->C c. Jika A->B digabungkan dengan $A->C$, maka ada 3 kemungkinan hasil: $\mathrm{A}->\mathrm{B}, \mathrm{C}$, dan $\mathrm{A}->\mathrm{B}-$ $>\mathrm{C}$ dan $\mathrm{A}->\mathrm{C}->\mathrm{B}$

Dari setiap kemungkinan ini kemudian mengecek nilai supportnya apakah memenuhi min_sup atau tidak. Jika ya maka sequence itu termasuk dalam frequent $k$-sequence. Pencarian frequent sequence dihentikan apabila tidak ada frequent ( $\mathrm{k}-1)$ sequence yang bisa digabung atau sudah tidak ditemukan frequent $k$-sequence lagi.

Pembentukan Rule Setelah ditemukan semua frequent sequence, ditentukan rule dari sequencesequence tersebut. 1 -sequence tidak digunakan untuk membentuk rule karena hanya terdiri dari 1 item. Untuk 2-sequence yang menjadi antecedent adalah item pertama dan consequentnya adalah item kedua. Contohnya untuk sequence A->B maka rule yang dibentuk adalah $\mathrm{A}=>\mathrm{B}$. sedangkan untuk sequence yang panjangnya lebih dari 2 atau ksequence, yang dijadikan consequent adalah item terakhir, sedangkan antecedentnya adalah semua item sebelum item terakhir. Contohnya pada 4- sequence A->B->C->D, maka rule yang dihasilkan adalah A$>\mathrm{B}->\mathrm{C}=>\mathrm{D}$. Untuk masingmasung rule dihitung nilai confidence-nya serta nilai support. Rule yang memenuhi atau melebihi dari nilai minimum confidence dan minimum support merupakan rule yang digunakan dan kemudian untuk dihitung lift rationya untuk menentukan rule mana yang paling kuat.

\section{II.5.1 SUPPORT AND CONFIDENCE}

Support merupalan ukuran yang menunjukan besar tingkat dominasi suatu item atau itemset keseluruhan transaksi. Support digunakan untuk rule yang memiliki nilai kurang dari threshold (Yunianto et al., n.d.). Untuk menentukan support dapat dilihat pada persamaan 1:

$$
\operatorname{Supp}(\mathrm{A} \rightarrow \mathrm{B})=\frac{\text { Jumlah transaksi itemset }(A \rightarrow B)}{\text { Total transaksi }}(1)
$$

Confidence adalah ukuran yang menunjuakn hubungan antara dua item secara kondisional. Confidence adalah rasio antara jumlah transaksi yang meliputi semua item dalam antecendent dan consequent dengan jumlah transaksi meliputi semua item dalam antecendent (Yunianto et al., n.d.). Untuk mencari nilai confidence dapat dilihat pada persamaan 2:

$$
\operatorname{Conf}(\mathrm{A} \rightarrow \mathrm{B})=\frac{\text { Jumlah Transaksi itemset }(\mathrm{A} \rightarrow \mathrm{B})}{\text { Jumlah antecendent } \mathrm{A}}(2)
$$




\section{II.5.2 LIFT RATIO}

Lift ratio dapat digunakan untuk mengetahui kuat tidaknya sebuah rule. Lift ratio dapat dihitung dengan cara membandingan nilai confidence dengan nilai benchmark confidence. Nilai dari benchmark confidence setiap rule didapatkan dari nilai jumlah transaksi consequent dibagi dengan jumlah transaksi. Untuk mencari nilai confidence dapat dilihat pada persamaan 3 , sedangkan rumus untuk mencari nilai lift ratio dapat dilihat pada persamaan 4 (Yunianto et al., n.d.).

$$
\begin{gathered}
\text { Benchmark Confidence }=\frac{n e}{n}(3) \\
\mathrm{nc}=\text { Jumlah transaksi item yang menjadi } \\
\text { consequent. } \\
\mathrm{n}=\text { Jumlah transaksi basis data } \\
\text { Lift Ratio }=\frac{\text { Confidence }}{\text { Benchmark Confidence }}
\end{gathered}
$$

\section{Analisis dan Perancangan}

\section{III.1 Gambaran Umum Sistem}

Sistem yang akan dibangun merupakan sebuah sistem yang menerima input berupa event log dari Igracias Universitas Telkom. Data tersebut akan melalui tahap preprocessing untuk membersihkan data yang tidak dibutuhkan agar sesuai dengan kebutuhan sistem. Selanjutnya data hasil preprocessing masuk pada tahapan pattern discovery dengan algoritma Sequential Pattern Mining Using Equivalence Classes (SPADE). Dan hasil dari proses pattern discovery adalah frekuensi pola pengaksesan user. Setelah mendapatkan hasil dari pattern discovery, dilakukan pattern analysis yaitu dengan membentuk rule yang diuji menggunakan nilai lift ratio, apabila nilai lift ratio lebih dari 1 maka rule dianggap kuat. Adapun tahapan proses sistem dapat dilihat pada gambar 2 dibawah ini.

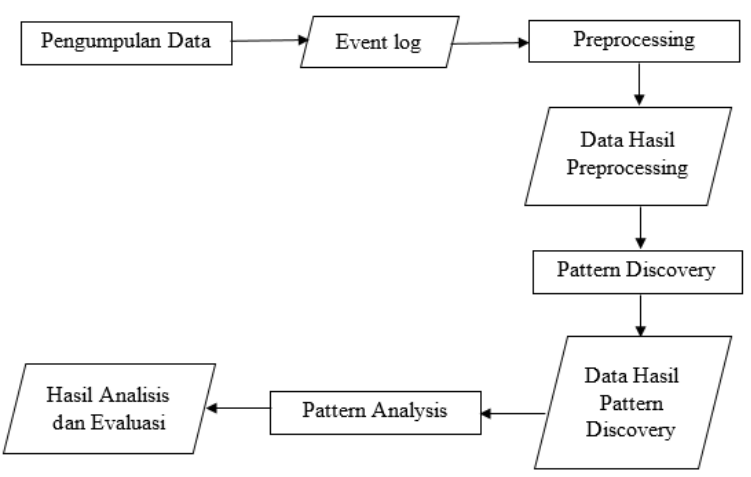

Gambar 2 Tahapan Proses Sistem

\section{III.2 Gambaran Umum Sistem}

Berikut adalah hasil pengujian yang dilakukan sesuai dengan skenario yang telah ditentukan dan disertai dengan analisis hasil pengujian.

a. Pengujian dengan membandingkan perhitungan manual dan perhitungan sistem

Pengujian dengan membandingkan perhitungan manual dengan perhitungan sistem dilakukan dengan menggunakan beberapa sampel data dan kemudian dihitung akurasinya secara manual dengan algoritma yang digunakan pada sistem. Data sample yang digunakan yaitu terdiri dari 36 data record yang diambil dari data mahasiswa. Dari data tersebut kemudian dilakukan preprocessing, pattern discovery dan pattern analysis. Dari data sample yang ada didapatkan 11 eksekutor yang berbeda dengan 14 jenis aktivitas. Pengujian pada perhitungan manual menghasilkan perhitungan seperti pada tabel 1 .

Pengujian perhitungan sistem dilakukan dengan sample data yang sama yaitu yang terdiri dari 36 data record. Output dari evaluasi ini menggambarkan bahwa perhitungan dari sistem dengan perhitungan manual yang dilakukan oleh penulis menghasilkan output yang sama. Hasil dari perhitungan sistem ditunjukan pada gambar 3 . 
Tabel 1 Hasil Perhitungan Manual SPADE pada Sample Data

\begin{tabular}{llllll}
\hline \hline ID & Eksekutor & Support & Confidence & B-Conf & $\begin{array}{c}\text { Lift } \\
\text { Ratio }\end{array}$ \\
\hline \hline 1 & 19824 & $14 \%$ & $63 \%$ & $28 \%$ & 2,25 \\
2 & 21006 & $28 \%$ & $100 \%$ & $28 \%$ & 3,6 \\
3 & 48693 & $3 \%$ & $20 \%$ & $3 \%$ & 7,2 \\
3 & 48693 & $3 \%$ & $100 \%$ & $28 \%$ & 3,6 \\
4 & 49821 & $6 \%$ & $40 \%$ & $14 \%$ & 2,88 \\
5 & 51899 & $3 \%$ & $100 \%$ & $14 \%$ & 7,2 \\
6 & 53848 & $8 \%$ & $30 \%$ & $14 \%$ & 2,16 \\
7 & 54303 & $6 \%$ & $40 \%$ & $14 \%$ & 2,88 \\
8 & 76621 & $3 \%$ & $100 \%$ & $3 \%$ & 36 \\
9 & 79170 & $8 \%$ & $38 \%$ & $8 \%$ & 4,5 \\
10 & 80571 & $14 \%$ & $100 \%$ & $14 \%$ & 7,2 \\
11 & 80811 & $8 \%$ & $38 \%$ & $8 \%$ & 4,5 \\
\hline \hline
\end{tabular}

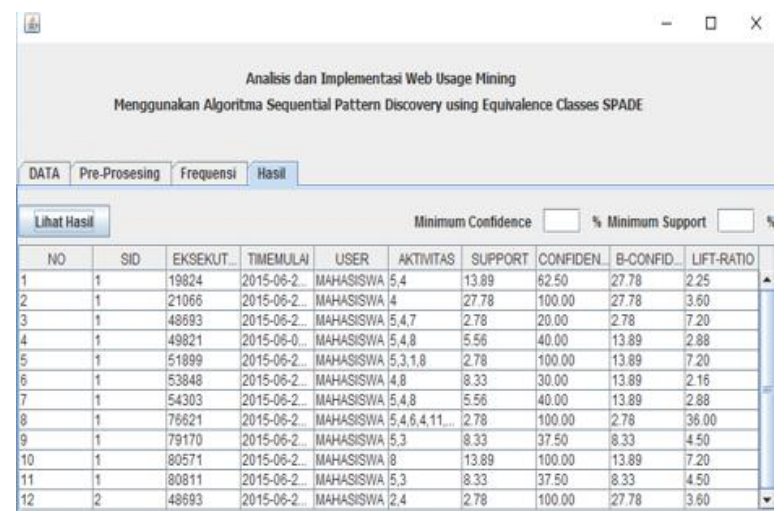

\section{Gambar 3 Hasil Perhitungan Sistem SPADE pada} Sample Data

b. Perhitungan dengan minimum support dan minimum confidence

Pengujian terhadap beberapa Minimum support dan minimum confidence dilakukan untuk melihat pengaruh nilai Minimum support dan minimum confidence terhadap lift ratio yang dihasilkan dan untuk mendapatkan Minimum support dan minimum confidence yang cukup. Hal ini dilakukan untuk melihat lift ratio mana yang kuat atau berpengaruh sehingga terlihat aktivitas mana yang sering dilakukan user. Pengujian berdasarkan Minimum support dan minimum confidence dilakukan untuk 3 kategori user yaitu mahasiswa, dosen dan pegawai. Pengujian ini dilakukan untuk mendapatkan minimum support dan minimum confidence yang sesuai untuk pengujian selanjutnya.

Untuk data mahasiswa pada tabel 2 akan digunakan Minimum support 5\%, 10\%, dan $20 \%$ dan dengan nilai minimum confidence $60 \%, 70 \%$ dan $80 \%$ Dari hasil uji coba data mahasiswa, perubahan yang terjadi tidak terlalu besar. Pada percobaan dengan Minimum support 5\%, terdapat 6 jenis aktivitas. Pada Minimum support $10 \%$ terdapat 3 jenis aktivitas. Dan pada Minimum support $20 \%$ terdapat 2 jenis aktivitas. Dari ketiga percobaan tersebut terdapat 3 menu yang selalu ada. Namun terdapat 3 jenis aktivitas yang berbeda pada minimum support 5\%. Untuk itu dari hasil percobaan tersebut diambil minimum support 5\% untuk data mahasiswa. Dan pada percobaan dengan minimum confidence $60 \%$, terdapat 6 jenis aktivitas. Pada minimum confidence $70 \%$ terdapat 6 jenis aktivitas. Dan pada minimum confidence $80 \%$ terdapat 5 jenis aktivitas. Pada minimum support $70 \%$ dan $80 \%$ terdapat perbedaan jumlah aktivitas yang dihasilkan. Untuk itu dari hasil percobaan tersebut diambil minimum confidence $70 \%$ untuk data mahasiswa.

Tabel 2 Data Mahasiswa dengan Minimum Support 5\% dan Minimum Confidence $70 \%$

\begin{tabular}{llllll} 
No. & Aktivitas & Support & Conf & B-conf & Lift ratio \\
\hline \hline 1 & 32 & 5,39 & 100 & 5,39 & 18,56 \\
2 & 92 & 7,11 & 100 & 7,11 & 14,06 \\
3 & 51 & 7,82 & 100 & 7,82 & 12,78 \\
4 & 45 & 21,57 & 100 & 21,57 & 4,64 \\
5 & 13 & 29,13 & 100 & 29,13 & 3,43 \\
6 & 45,13 & 16,86 & 78,15 & 29,13 & 2,68 \\
\hline \hline
\end{tabular}

Selanjutnya untuk data dosen pada tabel 3 akan digunakan minimum support 5\%, 10\%, dan $20 \%$ dan dengan nilai minimum confidence 40\%, 50\% dan $60 \%$. Dari hasil uji coba data dosen, perubahan yang terjadi tidak terlalu besar. Pada percobaan dengan minimum support 5\%, terdapat 9 jenis aktivitas. Pada minimum support $10 \%$ terdapat 5 jenis aktivitas. Dan pada minimum support $20 \%$ 
terdapat 1 jenis aktivitas. Dari ketiga percobaan tersebut terdapat minimum support 5\% menghasikan jumlah aktivitas yang lebih banyak sehingga terlihat aktivitas yang dilakukan oleh user. Untuk itu dari hasil percobaan tersebut diambil minimum support $5 \%$ untuk data dosen. Dan pada percobaan dengan minimum confidence $40 \%$, terdapat 8 jenis aktivitas. Pada minimum confidence 50\% terdapat 7 jenis aktivitas. Dan pada minimum confidence $60 \%$ terdapat 7 jenis aktivitas. Pada Minimum support $50 \%$ dan $60 \%$ memiliki jumlah aktivitas yang sama. Dan pada minimum support $40 \%$ terdapat 7 aktivitas yang dimiliki Minimum support 50\% dan 60\%. Untuk itu dari hasil percobaan tersebut diambil minimum confidence $40 \%$ untuk data dosen.

Tabel 3 Data Dosen dengan Minimum Support 5\% dan Minimum Confidence $40 \%$

\begin{tabular}{llllll}
\hline \hline No. & Aktivitas & Support & Conf & B-conf & Lift ratio \\
\hline \hline 1 & 63 & 6,98 & 100 & 6,98 & 14,32 \\
2 & 60 & 8,3 & 100 & 8,3 & 12,05 \\
3 & 25 & 15,21 & 100 & 15,21 & 6,57 \\
4 & 70 & 17,82 & 100 & 17,82 & 5,61 \\
5 & 9 & 18,82 & 100 & 18,82 & 5,31 \\
6 & 25,9 & 13,85 & 91,04 & 18,82 & 4,84 \\
7 & 59 & 22,12 & 100 & 22,12 & 4,52 \\
8 & 9,7 & 7,85 & 41,71 & 17,82 & 2,34 \\
\hline \hline
\end{tabular}

Selanjutnya untuk data pegawai pada tabel 4 akan digunakan minimum support 5\%, 10\%, dan 20\% dan dengan nilai minimum confidence $70 \%, 80 \%$ dan 90\%. Dari hasil uji coba data pegawai, perubahan yang terjadi tidak terlalu besar. Pada percobaan dengan minimum support 5\%, terdapat 6 jenis aktivitas. Pada minimum support $10 \%$ terdapat 4 jenis aktivitas. Dan pada minimum support $20 \%$ terdapat 3 jenis aktivitas. Dari ketiga percobaan tersebut terdapat 3 aktivitas yang selalu ada. Namun terdapat 3 jenis aktivitas yang berbeda pada minimum support $5 \%$ dan 2 perbedaan pada minimum support $10 \%$. Untuk itu dari hasil percobaan tersebut diambil minimum support $5 \%$ untuk data pegawai. Dan pada percobaan dengan minimum confidence $70 \%$, terdapat 6 jenis aktivitas. Pada minimum confidence $80 \%$ terdapat 6 jenis aktivitas. Dan pada minimum confidence $90 \%$ terdapat 5 jenis aktivitas. Pada minimum support $80 \%$ dan $90 \%$ terdapat perbedaan jumlah aktivitas yang dihasilkan. Untuk itu dari hasil percobaan tersebut diambil minimum confidence $80 \%$ untuk data pegawai.

Tabel 4 Data Pegawai dengan Minimum Support $5 \%$ dan Minimum Confidence $80 \%$

\begin{tabular}{llllll}
\hline \hline No. & Aktivitas & Support & Conf & B-conf & $\begin{array}{l}\text { Lift } \\
\text { ratio }\end{array}$ \\
\hline \hline 1 & 8 & 6,52 & 100 & 6,52 & 15,34 \\
2 & 70 & 6,81 & 100 & 6,81 & 14,68 \\
3 & 8,14 & 20,99 & 322,02 & 30,05 & 10,71 \\
4 & 48 & 20,68 & 100 & 20,68 & 4,83 \\
5 & 14 & 30,05 & 100 & 30,05 & 3,33 \\
6 & 48,14 & 18,41 & 89,01 & 30,05 & 2,96 \\
\hline \hline
\end{tabular}

c. Pengujian dengan perbandingan kalender akademik

Dari hasil aktivitas tiap bulan dan kalender akademik didapatkan beberapa persamaan yaitu:

- Pada data mahasiswa bulan Januari hasil dari aktivitas sistem adalah aktivitas 80: RegistrasiRegistrasi-Registrasi Mata Kuliah dan aktivitas 71: Registrasi-Cetak KSM sama dengan yang ada pada agenda kalender akademik tanggal 516 Januari 2015.

- Pada data mahasiswa bulan Maret hasil dari aktivitas sistem adalah aktivitas 85: RegistrasiJadwal-Jadwal Ujian Mahasiswa sama dengan yang ada pada agenda kalender akademik 9-18 Maret 2015

Pada data mahasiswa bulan Mei hasil dari aktivitas sistem adalah aktivitas 32: Geladi-Pilih Lokasi dan aktivitas 92: Registrasi-Jadwal-Jadwal Ujian Mahasiswa. Aktivitas 32: Geladi--Pilih Lokasi berhubungan dengan agenda pada awal bulan juni dan aktivitas 92: Registrasi-Jadwal-Jadwal Ujian Mahasiswa sama dengan yang ada pada agenda kalender akademik 11-22 Mei 2015

Asri Inna Khoirun Nissa, Ibnu Asror, Gede Agung Ary W 


\section{KESIMPULAN DAN SARAN}

Berdasarkan dari hasil pengujian yang dilakukan. Hasil dari aktivitas yang dilakukan oleh sistem pada tiap bulannya berbeda dengan kalender akademik. Maka dari itu rekomendasi yang dapat dilakukan adalah dengan menambahkan menu input kalender akademik pada igracias. Menu ini nantinya berguna untuk membuat igracias menampilkan menu-menu yang sesuai berdasarkan inputan dari aktivitas yang ada pada kalender akademik. Berikut tampilan yang dapat diberikan berdasarkan hasil dari aktivitas yang ada pada sistem dari tiap user.

Tabel 3-5 Rekomendasi Menu Tiap User

\begin{tabular}{|c|c|c|}
\hline Mahasiswa & Dosen & Pegawai \\
\hline Cetak KSM & $\begin{array}{l}\text { Berita Acara } \\
\text { Perkuliahan }\end{array}$ & Data Pegawai \\
\hline $\begin{array}{l}\text { Jadwal Ujian } \\
\text { Mahasiswa }\end{array}$ & $\begin{array}{l}\text { Cetak Daftar } \\
\text { Hadir }\end{array}$ & Detail Penggajian \\
\hline Kehadiran & Cetak Presensi & Lihat Kehadiran \\
\hline Lihat Nilai & Data Perwalian & Pendaftaran Rekreasi \\
\hline $\begin{array}{l}\text { Lihat Nilai } \\
\text { Semester }\end{array}$ & Submit BAP & Pengajuan Cuti \\
\hline Pilih Lokasi & & $\begin{array}{l}\text { Persetujuan Beban } \\
\text { Kerja Pegawai }\end{array}$ \\
\hline $\begin{array}{l}\text { Registrasi Mata } \\
\text { Kuliah }\end{array}$ & & Ubah Password \\
\hline
\end{tabular}

Dari semua pengujian tersebut dihasilkan bahwa minimum support yang sesuai untuk data mahasiswa adalah $5 \%$ dan minimum confidence nya adalah $70 \%$. Minimum support untuk data dosen adalah 5\% dan minimum confidence nya adalah $40 \%$. Sedangkan untuk data pegawai menggunakan minimum support $5 \%$ dan minimum confidence $80 \%$. Hal ini dapat berbeda karena jumlah data dari tiap user berbeda dan pengaruh dari besarnya nilai support dan confidence pada setiap user.

\section{REFERENSI}

Gunawan, R. J. (2015). SEQUENTIAL PATTERN MINING DENGAN SPADE UNTUK PREDIKSI PEMBELIAN SPARE PART DAN AKSESORIS KOMPUTER PADA KEDATANGAN KEMBALI KONSUMEN, 314-325.

Hermawan, A. A. (2014). Analisis Konteks Proses Bisnis Berdasarkan " Event Log” Business Process Context
Analysis Based on "Event Log," 4(3), 133-150.

Mehak, Kumar, M., \& Aggarwal, N. (2013). Web usage mining: An analysis. Journal of Emerging Technologies in Web Intelligence, 5(3), 240-246. https://doi.org/10.4304/jetwi.5.3.240-246

Mooney, C. H., \& Roddick, J. F. (2013). Sequential Pattern Mining - Approaches and Algorithms, 45(2). https://doi.org/10.1145/2431211.2431218.

Valera, M., \& Chauhan, U. (2013). An efficient web recommender system based on approach of mining frequent sequential pattern from customized web log preprocessing. 2013 4th International Conference on Computing, Communications and Networking Technologies, $\quad$ ICCCNT 2013. https://doi.org/10.1109/ICCCNT.2013.6726493

Varnagar, C. R., Madhak, N. N., Kodinariya, T. M., \& Rathod, J. N. (2013). Web usage mining: A review on process, methods and techniques. Proceeding of the Information Communication and Embedded Systems (ICICES), 2013 International Conference, 40-46.

https://doi.org/10.1109/ICICES.2013.6508399

Vijiyarani, S., \& Suganya, M. E. (2015). Research issues in web mining. International Journal of ComputerAided Technologies (IJCAx), 2(3), 55-64. https://doi.org/10.5121/ijcax.2015.2305

Yunianto, D. R., Dewi, C., Yudistira, N., Studi, P., Informatika, T., Brawijaya, U., \& Pola, P. (n.d.). SEQUENTIAL PATTERN MINING PADA PENCARIAN POLA PERILAKU PENGGUNA INTERNET MENGGUNAKAN ALGORITMA SPADE classes ) diterapkan untuk mencari pola perilaku pengguna internet dengan cara melakukan preprocessing data untuk menyaring informasi yang dibutuhkan . Di.

Zaki, M. J. (2001). SPADE: An Efficient Algorithm for Mining Frequent Sequences. Machine Learning, 42(1/2), $31-60$. https://doi.org/10.1023/A:1007652502315 